\title{
PENGARUH MEDAN MAGNET TERHADAP KECEPATAN REAKTAN PEMBAKARAN PREMIXED MINYAK JARAK DAN MINYAK KELAPA B25 KARAKTERISTIK NYALA API
}

\author{
Dionisius Agung \\ Teknik Mesin, Fakultas Teknik \\ Universitas Maarif Hasyim Latif, Sidoarjo, Indonesia \\ e-mail : dionisius-agung@student.umaha.ac.id
}

\begin{abstract}
ABSTRAK
Dengan meningkatnya pertumbuhan manusia yang sangat pesat saat ini semakin besar pula permintaan energi akan di hasilkan dari proses bahan bakar baru yang dipakai semakin menipis. Sehingga kita membutuhkan sumber daya baru untuk menggantikan bahan bakar yang baru yaitu minyak nabati. Minyak kelapa termasuk mbahan baakar minyk nabati dan asam lemak jenuh. salah satu yang berpengaruh terhadap karakteristik api Semakin besar eksploitasi bahan bakar minyak bumi membuat cadangan minyak bumi semakin menipis. "Cadangan minyak bumi Indonesia terus menurun dalam beberapa tahun terakhir akibat karna minyak dalam jumlah besar tdak ada yang belum ada yang menemukanterhadap karakteristik api pembakaran seprti minyak nabati B25 adalah. Dengan variasi medan magnet akan terlihat karakteristik api dari pembakaran premixed minyak nabati B25 minyak kelapa pada burner. Metode penelitian secara eksperimental dengan memanaskan minyak nabati B25 hingga berbentuk uap, kemudian disalurkan ke burner yang nantinya akan diberikan udara yang dikontrol massa alirnya. Kemudian api dinyalakan dan massa alir udara dinaikkan hingga api terjadi lift off hingga blow off. Dua buah magnet diletakkan diantara burner dengan memvariasikan arah medan magnet tolak dan Tarik dan banyaknya jumlah variasi medan magnet akan menyebabkan pengaru medan terhadap $\mathrm{Vu}$ kecepatan reaktan.
\end{abstract}

Kata kunci: pengaruh , medam magnet, minyak nabati B25 pembakaran premixed.

\section{PENDAHULUAN}

Dengan meningkatnya pertumbuhan manusia yang sangat pesat saat ini semakin besar pula permintaan energi yang untuk di hasilkan pembakarn hampir setiap kebutuhan energi manusia saat ini dihasilkan dari proses pembakaran. begitu juga manusia indonesia juga sangat bergantung pada energi. untuk saat ini energi yang pembkaran akan di hasikan melallu proses rata-rata yang di gunakan adalah bahan bakar minyak bumi yang tidak bisa diperbaharui, baik untuk menggerakkan mesin mesin pembakaran seperti mesin industri, alat transportasi, pembangkit listrik hampir semua memakai bahan bakar minyak bumi. serakarang ya ng paling banyak yang di pembkaran minyak bumi rata-rata yang di gunakan bahan bakar minyak bumi yang tidak bisa diperbaharui, semakin menipis. Cadangan minyak bumi Indonesia terus menurun pada beberapa tahung beberapa tahun terakhir ini akibat karena belum ada penemuan bahan bakar yang bnyak besarBerbagai penelitian tentang minyak nabati dilakukan yang minyak nabati sebagai minyak alternatife yang untuk pengganti bahan bakar minyak bumi. Penelitian minyak nabati yang dapat untuk melakukan penelitian atau mem buktikan bahwa bisa mendpatkan bahan bakar terbarukan, yaitu adalah minyak nabati lainnya seperti minyak kelapa murni,minyak jarak pagar,miynak biji kapas atau minyak nabati biji kapuk dan lain sebaginya.

Pada pengujian kali ini akn mencari atau menggali lebih dalam untuk mengetahui tentang karakteristik nyala api pembakaran yang berakibat induksi medan magnet dengan minyak nabati kelap murni dan minyak jarak,dengan mengharapkan mendapatkan tingkat temperature yang dari pembentukan warna nyala api,serta membuktikan bahwa profil atau gambar nyala api yang bermuara pada metode analisis pembakaran minyak nabati secara luas, dari uji pertama kali yang di lihat bentuk atau warn api dari proses pembakarn bahan bakar nabati dari minyak kelapa dan minyak minyak jarak. Sehingga diharapkan pada penelitian awal ini dapat diketahui seberapa besar induksi medan magnet berpengaruh variasi arah medan mangnet dan tanpa medan magnet 
pada $(\mathrm{Vu})$ kecepatan reaktan terhadap bentuk nyala api,tinggi nyala api,temperature nyala api,kecepatan paembakaran laminar tanpa medan magnet, magnet tolak,dan magnet tarik yang dapat diamati dengan menggunakan metode visualisasi nyala api premix dengan cara sebagai berikut alat ukur hasil pengukuran dibandingkan dengan media lain, Alat perekam atau camera dikoneksikan ke komputer pada jalur audio input, pada saat pengambilan data diupayakan kondisi lingkungan gelap/malam hari sehingga gambar profil api tampak jelas, dilakukan dengan waktu yang di tentukan. Hasil rekaman disimpan sebagai data, proses rekaman dapat diulang lagi sampai 3 pengulangan, import file data, dilakukan visualisasi gambar nyala api.

\section{METODE PENELITIAN}

Perencanaan penelitian merupakan proses awal dari kegiatan biar dapat hasil yang bagus sesuai diinginkan, setelah perencanaan awal sampai selesai maka pelaksanaan penelitian bisa dilakukan. Penelitian ini dimulai dari studi literatur yaitu mempelajari jurnal penelitian sebelumnya tentang pembakaran minyak nabati melakukan observasi alat yang akan digunakan sebagai penelitian maupun eksperimen kemudian melakukan persiapan minyak B25 minyak jarak (75\%),minyak kelapa (25\%) dan volume minyak ,minyak jarak (450ml) dan minyak kelapa (25ml) dan selanjutnya persiapn persiapan intalasi pembakran pertama alat dan bahan yang dibutuhkan, setelah itu proses perakitan alat uji, selanjutnya pengujian alat apabila masih terdapat kesalahan maka dilakukan proses pengujian ulang sampai mendapat data yang relevan, setelah pengujian berhasil bisa dilakukan proses pengambilan data kemudian dianalisa hasil data penelitian tersebut dan penyusunan laporan bisa dilakukan. Adapun instalasi pembakaran premixed minyak nabati B25 pada gambar 1 sebagai berikut :

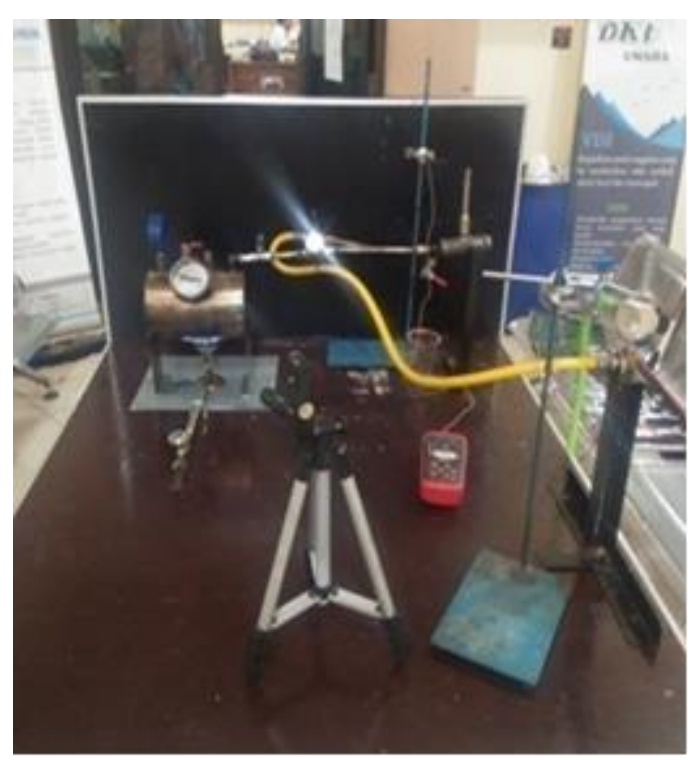

\author{
ALAT \\ 1.Tabung Bunsen \\ 2. termometer \\ 3.presure gauge \\ 4. barel dan burner \\ 5. Kompresor angin \\ 6. Tercouple \\ 7. Statif dab Clem \\ 8. camera DLSR \\ 9. flow meter valve \\ 10. magnet \\ 11. pipa $U$ \\ BAHAN \\ 1. minyak jarak \\ 2. minyak kelapa
}

Tempat dan waktu kegiatan

a. Persiapan bahan baku minyak jarak dan minyak kelapa kelapa di olah sendiri dari buah kelapa Minyak jarak dibeli di online shop (toko minyak jarak SHOPEE).

b. Penelitian ini dilakukan di Di laboratorium Teknik Mesin Universitas Ma'arif Hasyim Latif. alamat di JL. Raya Ngelom Megare No 30 Megare, Taman, Sidoarjo, Jawa Timur

Pengujian alat pembakarn premixed menggunakan jenis minyak nabati B25 minyak kelapa pengujian ini di lakukan dengan cara sebagai berikut mula-mula bahan bakar atu minyak nabati dimasukkan kedalam burner,kemudian burner dibakar sampai menjadi uap dengan tekanan mencapai 3Bar dan temperatur didalam burner mencapai \pm 350 - 400oC. Uap didalam burner akan mengalir menuju steam trap.Valve dibuka jika tekanan dan suhu pada burner telah sesuai dengan prosedur.Uap yang mengalir dari valve akan menuju ke oriface plate.uap yang masuk kedalam oriface plate akan menimbulkan perbedaan tekanan sebelum dan sesudah melewati oriface plate, perbedaan tekanan tersebut akan diketahui oleh naik turun air didalam pipa U.naik turun air didalam pipa U dapat diatur dengan memperbesar dan memperkecil aliran uap divalve, sesuai dengan prosedur yang telah ditentukan.Uap yang telah melewati oriface plate akan menuju ke burner yang telah dilengkapi dengan magnet disisi kanan dan kiri.Kemudian uap keluar dari burner dibakar tanpa variasi udara hingga difusi.Setelah api mencapai difusi, compressor dinyalakan hingga tekanan udara didalam tabung compressor mencapai \pm 7 bar.Kemudian udara dialirkan dari compressor menuju ke flow meter valve.Udara yang mengalir dari flow meter valve akan menuju ke oriface plate.udara yang masuk kedalam oriface plate akan menimbulkan perbedaan tekanan sebelum dan sesudah melewati oriface plate, perbedaan tekanan tersebut akan diketahui oleh naik turun air didalam pipa U.Naik turun air didalam pipa $U$ dapat diatur dengan memperbesar dan memperkecil aliran udara di flow meter valve sebagai variasi aliran udara yang mengalir.Udara yang telah melewati oriface plate akan tercampur dengan 
uap/bahan bakar sebelum menuju ke burner. untuk proses pengolahan data menggunakan di rekam saat pengambilan data setelah di rekam di masukan data rekaman data masukin di aplkiasi computer/ atau laptop yaitu software free video to JPG converter, image j, dan software corel draw x7.

\section{HASIL DAN PEMBAHASAN}

Mencari debit udara dan bahan bakar (q) dari masing-masing jenis pengujian besarnya laju debit aliran udara diperoleh dengan membandingkan besarnya tekanan udara masuk yang telah diperoleh melalui pembacaan air flow manometer. Pada pengujian ini yang kami variasikan adalah debit aliran udara, sedangkat debit bahan bakar tetap. dimana dihitung berdasarkan rumus berikut:

Udara masuk yang telah diperoleh melalui pembacaan air flow manometer. Pada pengujian ini yang kami variasikan adalah debit aliran udara,

sedangkat debit bahan bakar tetap. Dimana dihitung berdasarkan rumus berikut:

$$
=\frac{\mathrm{CD} \times \mathrm{A} 1 \times \mathrm{A0} \sqrt{2 \times \mathrm{gx} \Delta \mathrm{h}}}{\sqrt{\mathrm{A1}^{2} \times \mathrm{A0}^{2}}}
$$

Cd / koefisien discharge

$$
=0,68-0,72
$$

A0 diameter luar oriface plate

$$
=10 \mathrm{~mm}
$$

A1 diameter lubang tengah oriface plate

G (gravitasi)

$$
=1 \mathrm{~mm}
$$

$$
=9800^{\mathrm{mm} / \mathrm{s}}
$$

$\Delta \mathrm{h}$ bahan bakar

$$
=2 \mathrm{~mm}
$$

Hasil perhitungan luas penampang oriface plate:

$$
\mathrm{A} 0=\frac{\pi}{4} \times 1 \mathrm{~mm} \times 1 \mathrm{~mm}=\frac{\frac{3,14}{4}}{\pi}=0,785 \mathrm{~mm}^{2}
$$

$$
\text { A1 }=\frac{\pi}{4} \times 10 \mathrm{~mm} \times 10 \mathrm{~mm}=\frac{314}{4}=78,5 \mathrm{~mm}^{2} \text { hasil }
$$

perhitungan mencari $q$ bahan bakar :

$$
\text { Q b.bakar }=\frac{\text { CD xA1 x A0 } \sqrt{2 \times \mathrm{gxh}}}{\sqrt{\mathrm{A1}^{2} \times \mathrm{A0} 0^{2}}}
$$

$0,68 x 78,5 \mathrm{~mm}^{2} x 0,785 \mathrm{~mm}^{2} \sqrt{2 x 9800 \mathrm{~mm} / \mathrm{s}^{2} x 2 \mathrm{x}, 1,0} 5$
Karena q bahan bakar tidak divariasikan maka q bahan bakar diasumsikan tetap $0,1058 \mathrm{~cm}^{3} / s$. Hasil perhitungan mencari q udara : q udara $=$

$$
\begin{gathered}
\mathrm{CD} \times \mathrm{A} 1 \times \mathrm{A0} \sqrt{2 \times \mathrm{g} \times \mathrm{h}} \\
\sqrt{\mathrm{A1}^{2} \times \mathrm{A0} 0^{2}} \\
\mathrm{Qudara}=
\end{gathered}
$$

$$
\begin{gathered}
\frac{0,68 \times 78,5 \mathrm{~mm}^{2} \times 0,785 \mathrm{~mm}^{2} \sqrt{2 x 9800 \mathrm{~mm} / \mathrm{s}^{2} \times 4 \mathrm{~mm}}}{\sqrt{\left(78,5 \mathrm{~mm}^{2}\right)^{2}-\left(0,785 \mathrm{~mm}^{2}\right)^{2}}} \\
\frac{41,9 \mathrm{~mm}^{2} \times 280 \mathrm{~mm} / \mathrm{s}}{\sqrt{6162,2 \mathrm{~mm}^{4}}-0,61 \mathrm{~mm}^{4}} \\
\text { Qudara }=\sqrt{11732 \mathrm{~mm}^{5}} \\
\sqrt{6161,59 \mathrm{~mm}^{4}}=\frac{11732 \mathrm{~mm}^{5}}{78,49 \mathrm{~mm}^{2}}
\end{gathered}
$$

Q udara divariasikan setiap penambahan pada pipA $U$ udara $\Delta$ h udara naik sebanyak $4 \mathrm{~mm}$

\section{bahan bakar}

Hasil rumus perhitungan $\dot{m}$ udara dan $\dot{m}$

Besarnya laju aliran udara (m udara) diperoleh dengan membandingkan besarnya tekanan udara masuk yang telah diperoleh melalui pembacaan air flow manometer. Pada pengujian ini dimana $\rho_{\text {udara }}=0.001164$ gram $/ \mathrm{cm}^{3}$ dan massa densitas $\rho$ bahan bakar $=$ 0,00026 gram $/ \mathrm{cm}^{3}$. Maka di diselesaikan dalam perhitungan berikut:

Diketahui : $\rho$ udara $=0.001164$ gram $/ \mathrm{cm}^{3}$

$\rho$ bahan bakar $\quad=0,00026$ gram $/ \mathrm{cm}^{3}$

Rumus mencari m udara dan bahan bakar adalah sebagai berikut: Rumus mencari m bahan bakar $\quad=\rho$ bahan bakar $\times \mathrm{Q}$ bahan bakar

Keterangan :

$\mathrm{cm}^{3}$

$\rho$ bahan bakar = $\quad=0,00026$ gram $/$

$\mathrm{cm}^{3}$

$$
\rho \text { udara } \quad=0,001164 \text { gram } /
$$

$$
\begin{array}{ll}
\text { Q bahan bakar } & =0,1058 \mathrm{~cm}^{3} / s \\
\text { Q udara } & =0,1494 \mathrm{~cm}^{3} / s \\
\text { m bahan bakar } & =0,00026 \text { gram/ }[\mathrm{cm} \rrbracket \wedge 3
\end{array}
$$

$$
\begin{gathered}
\text { Q b.bakar }=\sqrt{\frac{41,9 \mathrm{~mm}^{2} x 197,98 \mathrm{~mm} / \mathrm{s}}{6162,2 \mathrm{~mm}^{4}}-0,61 \mathrm{~mm}^{4}} \\
\frac{8295,36 \mathrm{~mm}^{5}}{\sqrt{6161,59 \mathrm{~mm}^{4}}}=\frac{8295,36 \mathrm{~mm}^{5}}{78,49 \mathrm{~mm}^{2}} \\
\text { Q b.bakar }=\frac{105,8 \mathrm{~mm}^{3} / \mathrm{s}}{1000}=0,1058 \mathrm{~cm}^{3} / \mathrm{s}
\end{gathered}
$$

\section{[cm \^3/_s = 0,0001739 gram/s}

Perbandingan Bentuk Nyala Api Minyak Blending B25 minyak Kelapa Tanpa Magnet terhadap kecepatan reaktan ( $\mathrm{Vu}$ ) tanpa medan magnet,magnet tolak,magnet tarik

Berikut merupakan Analisa dari hasil pengujiian pembakaran premixed dengan menggunakan bahan bakar nabati B25 minyak kelapa . Pada gambar 2 ialah pengujian secara actual untuk mengetahui bentuk nyala api nyala api minyak blending B25 dengan variasi tanpa 
medan magnet, magnet tolak,magnet tarik terhadap kecepatan reaktan
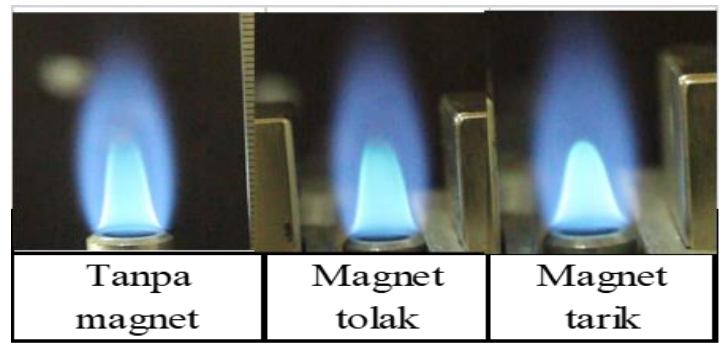

Gambar 2 perbandingan bentuk nyala api tanpa magnet, magnet tolak,magnet tarik

Pada gambar di lihatkan pada bentuk nyala api tanpa medan magnet dan menunnjukan kerucut dalam mulai terbentuk dari kecepatan reakta (vu) $1,96 \mathrm{~cm} / \mathrm{s}$ sampai ke bentuk nyala api 0,60.di 3 variasi penelitian yaitu: tanpa medan magnet,magnet tolak,magnet tarik di dapatkan nyala api tanpa magnet tdak begitu bagus titik nyala api.

Perbandingan tinggi nyala api minyak blending b25 minyak kelapa tanpa magnet terhadap kecepatan reaktan (vu) tanpa medan magnet,magnet tolak,magnet tarik

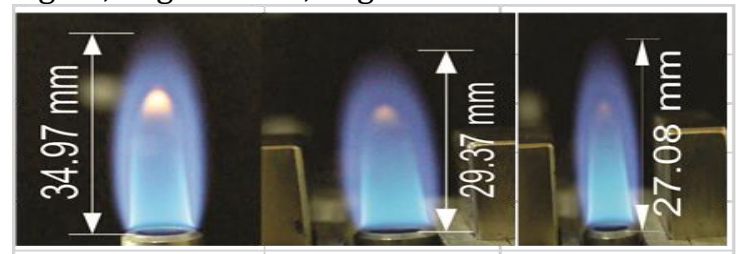

Tanpa magnet Magnet tolak Magnet tarik

Gambar 3 tinggi nyala api tanpa medan magnet, magnet tolak magnet tarik.

Pada gambar 4 di lihatkan pada bentuk nyala api medan magnet tolak dan menunnjukan kerucut dalam mulai terbentuk dari kecepatan reaktan (vu) 1,66 cm/s sampai ke bentuk nyala api $2,61 \mathrm{~cm} / \mathrm{s}$. Dengan nyala api yang kurang terang dan titik nyala api lebih terang dari tanpa medan magnet.

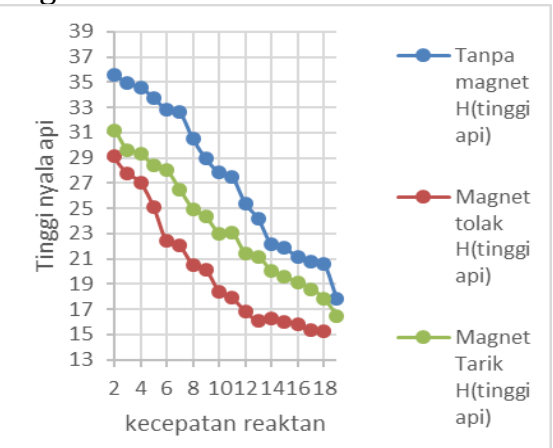

Gambar 4 grafik hubungan kecepatan reaktan terhadap tinggi nyala api tanpa medan magnet,magnet tolak,magnet tarik
Tabel 1 perbandingan hubungan kecepatan reaktan terhadap tinggi nyala api tanpa magnet,magnet tolak, magnet tarik.

\begin{tabular}{|c|c|c|c|}
\hline $\mathbf{V}_{\mathbf{U}}$ & Tanpa magnet & Magnet tolak & Magnet Tarik \\
\hline 0,9 & $\mathbf{H}_{\text {(tinggi api) }}$ & $\mathbf{H}_{\text {(tinggi api) }}$ & $\mathbf{H}_{\text {(tinggi api) }}$ \\
\hline 1,12 & 36,63 & 31,67 & 31,67 \\
\hline 1,29 & 35,63 & 29,12 & 31,22 \\
\hline 1,43 & 34,97 & 27,78 & 29,63 \\
\hline 1,55 & 34,57 & 27,08 & 29,37 \\
\hline 1,66 & 33,78 & 25,14 & 28,4 \\
\hline 1,77 & 32,81 & 22,41 & 28,05 \\
\hline 1,87 & 32,63 & 22,05 & 26,51 \\
\hline 1,96 & 30,52 & 20,55 & 24,96 \\
\hline 2,04 & 28,93 & 20,16 & 24,34 \\
\hline 2,12 & 27,87 & 18,42 & 23,02 \\
\hline 2,2 & 27,52 & 17,93 & 23,11 \\
\hline 2,28 & 25,4 & 16,85 & 21,42 \\
\hline 2,35 & 24,17 & 16,11 & 21,19 \\
\hline 2,42 & 22,14 & 16,32 & 20,02 \\
\hline 2,48 & 21,87 & 16,04 & 19,62 \\
\hline 2,54 & 21,17 & 15,77 & 19,09 \\
\hline 2,61 & 20,81 & 15,36 & 18,61 \\
\hline 2,72 & 20,64 & 15,26 & 17,84 \\
\hline 2.74 & 17,82 & & 16,47 \\
\hline & & & 15,35 \\
\hline
\end{tabular}

Pada gambar 4 di lihatkan pada bentuk nyala api medan magnet tolak dan menunnjukan kerucut dalam mulai terbentuk dari kecepatan reaktan (vu) $1,66 \mathrm{~cm} / \mathrm{s}$ sampai ke bentuk nyala api $2,61 \mathrm{~cm} / \mathrm{s}$. Dengan nyala api yang kurang terang dan titik nyala api lebih terang dari tanpa medan magnet berikut adalah tabel perbnadingan hhubungan kecepatan reaktan terhadap temperature tanpa medan magnet,magnet tolak,magnet Tarik.

\begin{tabular}{|c|c|c|c|}
\hline & Tanpa magnet & Magnet tolak & Magnet tarik \\
\hline $\mathbf{V}_{\mathbf{U}}$ & Temp & Temp & Temp \\
\hline 0,9 & 438 & 410 & 423 \\
\hline 1,12 & 458 & 422 & 430 \\
\hline 1,29 & 465 & 433 & 434 \\
\hline 1,43 & 474 & 442 & 440 \\
\hline 1,55 & 483 & 458 & 450 \\
\hline 1,66 & 503 & 477 & 461 \\
\hline 1,77 & 537 & 514 & 473 \\
\hline 1,87 & 570 & 554 & 491 \\
\hline 1,96 & 597 & 569 & 499 \\
\hline 2,04 & 616 & 596 & 510 \\
\hline 2,12 & 632 & 613 & 520 \\
\hline 2,2 & 644 & 633 & 532 \\
\hline 2,28 & 650 & 638 & 544 \\
\hline 2,35 & 655 & 632 & 560 \\
\hline 2,42 & 645 & 611 & 566 \\
\hline 2,48 & 635 & 582 & 571 \\
\hline 2,54 & 618 & 567 & 568 \\
\hline 2,61 & 605 & 534 & 556 \\
\hline 2,72 & & 514 & 543 \\
\hline 2,74 & & & 537 \\
\hline & & & \\
\hline
\end{tabular}




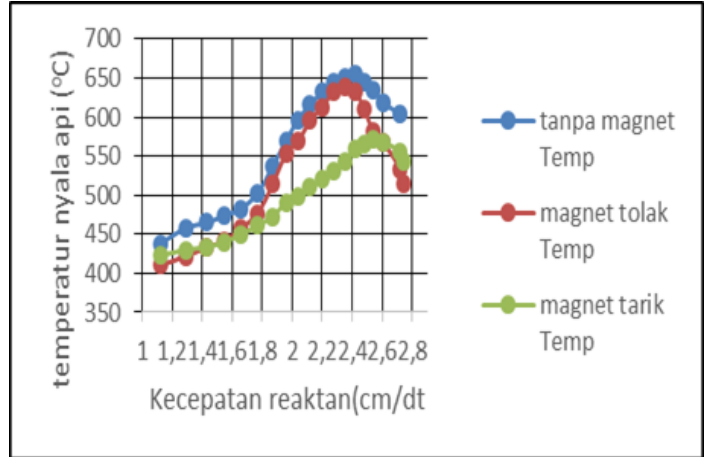

Gambar 5 grafik perbandingan hubungan kecepatan reaktan terhadap temperature nyala api tanpa medan magnet,magnet tolak,magnet tarik. Dari hasil yang diperoleh gambar 5 dapat dilihat temperatur nyala api medan magnet tarik paling tinggi sebesar 560 oc, temperatur tertinggi medan magnet tolak sebesar 638 oc, kemudian disusul temperatur nyala api tanpa medan magnet tertinggi adalah 655 oc.

Berikut gambar perbandingan hubungan kecepatan reaktan terhadap pembakaran laminer tanpa magnet,manet tolak,magnet tarik

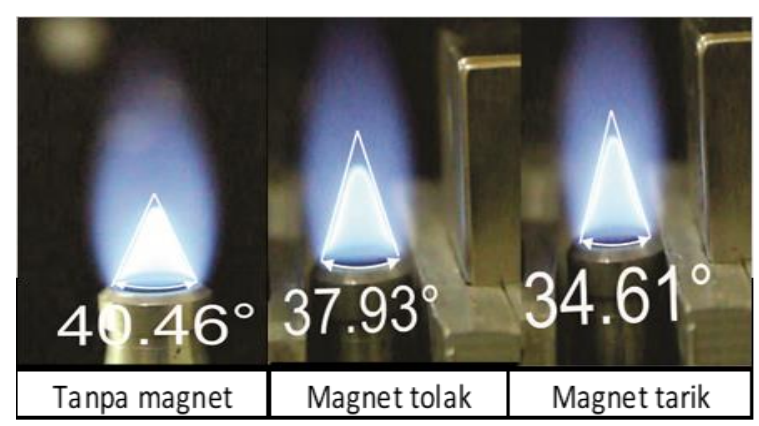

Gambar 5 perbandingan hubungan kecepatan reaktan terhadap pembakaran laminer nyala api tanpa medan magnet,magnet tolak,magnet tarik.

Tabel 3 perbandingan hubungan kecepatan reaktan terhadap pembkaran laminar tanpa medan magnet,magnet tolak,magnet tarik.

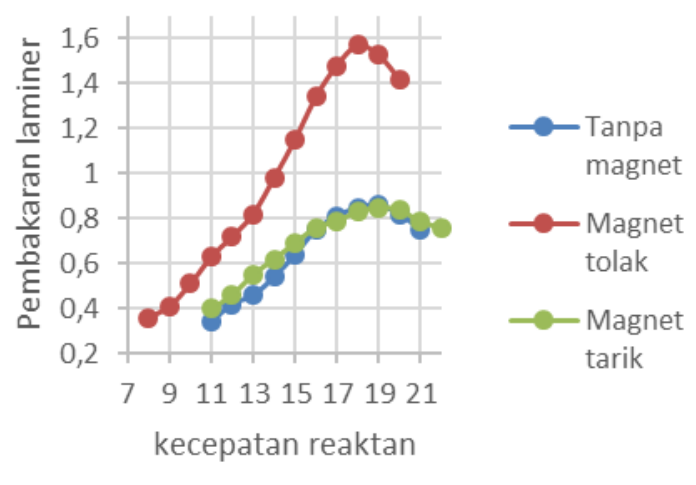

\begin{tabular}{|c|c|c|c|}
\hline & Tanpa magnet & Magnet tolak & Magnet tarik \\
\hline $\mathbf{V}_{\mathbf{U}}$ & $\mathbf{S}_{\mathbf{L}}$ & $\mathbf{S}_{\mathbf{L}}$ & $\mathbf{S}_{\mathbf{L}}$ \\
\hline 0,9 & & & \\
\hline 1,12 & & & \\
\hline 1,29 & & & \\
\hline 1,43 & & & \\
\hline & & & \\
\hline 1,55 & & & \\
\hline 1,66 & & 0,36 & \\
\hline 1,77 & & 0,41 & \\
\hline 1,87 & & 0,51 & \\
\hline 1,96 & 0,34 & 0,63 & 0,4 \\
\hline 2,04 & 0,42 & 0,72 & 0,46 \\
\hline 2,12 & 0,46 & 0,82 & 0,55 \\
\hline 2,2 & 0,54 & 0,98 & 0,62 \\
\hline 2,28 & 0,64 & 1,15 & 0,69 \\
\hline 2,35 & 0,75 & 1,34 & 0,76 \\
\hline 2,42 & 0,81 & 1,48 & 0,79 \\
\hline 2,48 & 0,85 & 1,57 & 0,83 \\
\hline 2,54 & 0,86 & 1,53 & 0,85 \\
\hline 2,61 & 0,82 & 1,42 & 0,84 \\
\hline 2,72 & 0,75 & & 0,79 \\
\hline 2,74 & & & 0,76 \\
\hline
\end{tabular}

Gambar 6 grafik pebandingan hubungan kecepata reaktan terhadap laju pembakarn laminar tanpa medan magnet,magnet tolak,magnet tarik.

dari hasil yang diperoleh gambar 4.21 dapat dilihat kecepatan pembakaran laminer terhadap kecepatan reaktan nyala api medan magnet tolak paling tinggisebesar $1,54 \mathrm{~cm} / \mathrm{s}$ dan medan magnet tolak sebesar $0,85 \mathrm{~cm} / \mathrm{s}$ kemudian disusul tanpa medan magnet tertinggi adalah $0,86 \mathrm{~cm} / \mathrm{s}$

\section{PENUTUP}

Dari hasil penelitian pengaruh medan magnet terhadap terhadap kecepan pembakarn premixed minyak jarak dan minyak kelapa b25 karakteristik nyala api,terdapat bentuk nyala api,tinggi nyala api,temperaur nyala api, kecepatan pembakarn laminar,tanapa manet, magnet tolak, dan magnet tarik terhadap kecepatan reaktan api dapat diambil kesimpulan sebagai berikut :

Bahwa medan magnet sangat berpengaruh terhapa ti ngging nyala api dalam pembakaran premixed karakterisrik nyala api dari hasil yang di amati sebegai berikut dari hasil yang di peroleh dapat di lihatkan pada bentuk nyala api medan magnet tarik dan menunnjukan kerucut dalam mulai terbentuk dari kecepatan reaktan (vu) 1,96 $\mathrm{cm} / \mathrm{s}$ sampai ke bentuk nyala api $2,42 \mathrm{~cm} / \mathrm{s}$. Dengan nyala

Semakin tinggi nyala api tekanan semakin turun diameter semakin renadah kecepatan reaktan semaakin renda dan tekan udara dari hasil yang diperoleh dapat dilihat tinggi nyala api tanpa medan magnet,magnet tolak,magnet tarik paling tinggi sebesar $36,63 \mathrm{~mm}$ tertinggi medan magnet tolak sebesar $31,67 \mathrm{~mm}$, kemudian disusul temperatur nyala api medan magnet tarik tertinggi adalah $31,67 \mathrm{~mm}$ dan kecepatan rektan adalah 0,90 $(\mathrm{cm} / \mathrm{dt}$ 
Temperatur nyala nyala api semakin tinggi tanpa magnet dan medan magnet tolak,magnet tarik terhadap kecepatan reaktan dapat dilihat sebagai berikut Dari hasil yang diperoleh dapat dilihat kecepatan pembakaran laminer terhadap kecepatan reaktan nyala api medan magnet tolak paling

\section{DAFTAR PUSTAKA}

Afifah, Y. N. (2019). Analysis of Unsteady Magneto Hydro Dynamic ( MHD ) Nano Fluid Flow Past A Sliced Sphere Analysis of Unsteady Magneto Hydro Dynamic ( MHD ) Nano Fluid Flow Past A Sliced Sphere. IOP Conference Series: Materials Science and Engineering, 494, 012033. https://doi.org/10.1088/1757899X/494/1/012033

B.N. Riwu, D., Wardana, I. N. G., \& Yuliati, L. (2016). Kecepatan Pembakaran Premixed Campuran Minyak Jarak - Liquefied Petroleum Gas (LPG) pada Circular Tube Burner. Jurnal Rekayasa Mesin, 7(2), 41-47. https://doi.org/10.21776/ub.jrm.2016.007.0 $\underline{2.1}$

Bahri La Muhaya, S., Wardana, I., \& Widhiyanuriyawan, D. (2015). Pembakaran Premixed Minyak Nabati pada Bunsen Burner Type Silinder. Jurnal Rekayasa Mesin, 6(1), 45-49. https://doi.org/10.21776/ub.jrm.2015.006.0 $\underline{1.7}$

Haq, M. Z. (1998). Fundamental Studies of Premixed Combustion. University of Leeds, (September). Retrieved from http://etheses.whiterose.ac.uk/id/eprint/154 $\underline{5}$

Haryanto, B. (2002). Bahan Bakar Alternatif Biodiesel (Bagian I. Pengenalan). USU Digital Library, (December), 1-13. https://doi.org/10.1007/s00340-003-1192-9

Jamrozik, A., Tutak, W., Pyrc, M., \& Sobiepanski, M. (2017). Effect of diesel-biodiesel-ethanol blend on combustion, performance, and emissions characteristics on a direct injection Diesel engine. Thermal Science, 21(1), 591-
604.

https://doi.org/10.2298/TSCI160913275J

Joelianingsih, Alghifari, M. I., \& Antika, F. M. (2016). Sintesis biodiesel dari minyak kemiri sunan dengan katalis homogen melalui reaksi esterifikasi dan transesterifikasi secara bertahap. (November), 1-11. https://doi.org/10.1093/inci/dju504

Kristanto, D. A. (2015). Pembakaran dan Karakteristik Bahan Bakar Cair. 1-4. Retrieved from www.academia.edu/10886751/Bahan Bakar DAN KARAKTERISTIKNYA\%0A

Pranoto, B., Hamidi, N., \& Wardana, I. N. . (2012). Pengaruh Variasi Air Fuel Ratio (Afr) Terhadap Karakteristik Api Pembakaran Premixed Minyak Kapuk Pada Burner. Seminar Hasil Konsentrasi Konversi Energi.

Rosli, N., Ambak, K., Daniel, B. D., Prasetijo, J., Tun, U., Onn, H., \& Pahat, B. (2015). Jurnal Teknologi. 1, 1-6.

Wirawan, I. K. G., Wardana, I. N. G., Soenoko, R., \& Wahyudi, S. (2013). All rights reserved Int. Journal of Renewable Energy Development, 2(3), 133-139. 